\title{
Applications of Airborne LiDAR Mapping in Glacierised Mountainous Terrain
}

\author{
Chris Hopkinson \\ Cold Regions Research Centre, Wilfrid Laurier University, 202 Regina St. Waterloo, Ont. Canada, N2L 3C5 \\ Mike Demuth \\ National Glaciology Program, Geological Survey of Canada, Booth St. Ottawa, Canada \\ Mike Sitar \\ Optech Inc. 100 Wildcat Rd. North York, Toronto, Ont. Canada \\ Laura Chasmer \\ Faculty of Environmental Studies, University of Waterloo, Waterloo, Ont. Canada
}

\begin{abstract}
The paper discusses logistics \& applications of the first complete airborne scanning LiDAR survey of a glacierised mountain basin. The survey was conducted over a $25 \times 6 \mathrm{~km}$ area with ground height variation from 1,800 masl to 3,400 masl. The resolution of survey points on the ground varied from 1 per sq metre to around 1 per 4 sq metres, depending on elevation. Correspondence from swath to swath is very good despite the extreme nature of the topography $\&$ individual ground laser heights are accurate to within $20 \mathrm{~cm}$. Glaciological applications for the high-resolution digital elevation data are outlined. Special attention is paid to radiation loading model-scaling issues.
\end{abstract}

\section{INTRODUCTION}

An airborne LiDAR survey of the Wapta Icefields in the Canadian Rockies was commissioned by the Geological Survey of Canada, National Glaciology Program [1] \& flown by Optech Inc. in October 2000. There were several objectives to this study \& this paper presents a preliminary overview of the project:

1) To assess the feasibility \& reliability of LiDAR surveys over high relief terrain of varied ground cover;

2) To test glaciological LiDAR applications [1];

3) To assess radiation loading scaling issues over glacierised mountainous terrain [2].

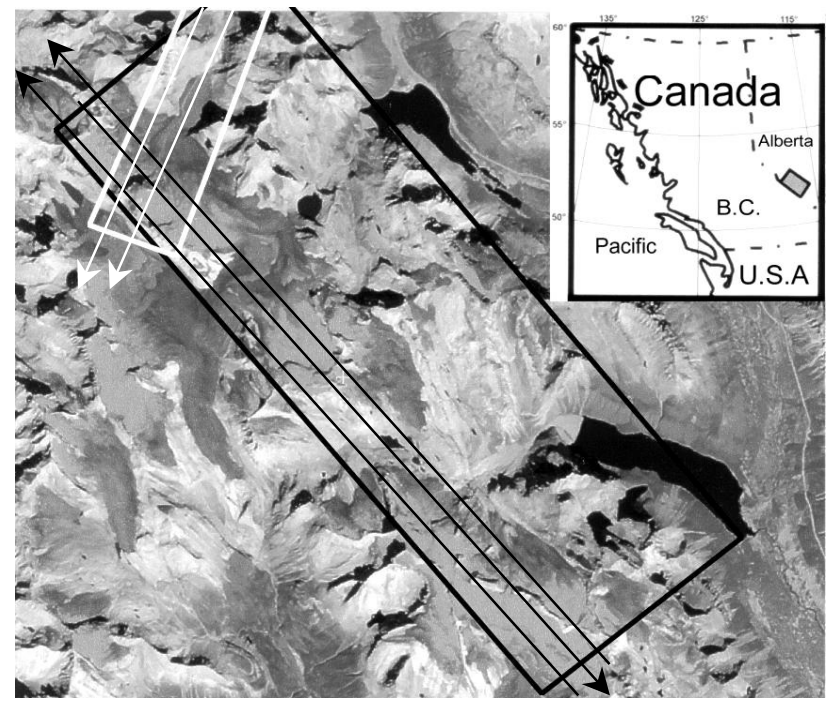

Fig. 1. Study area $\&$ survey flight polygons

The survey area is $25 \mathrm{~km}$ x $6 \mathrm{~km} \&$ straddles the Wapta Icefield on the continental divide of Western Canada (Fig. 1). The Icefield has been inventoried [3] \& recent volumetric losses estimated [4]. Glacier wastage constitutes a significant component of downstream water supply [5] \& therefore periodic high-resolution surface mapping of glacier areas would be very useful. No known wide coverage airborne LiDAR surveys have been undertaken over such high relief $(1800-3400$ masl $)$ and varied (glaciers, forests, lakes, bare rock) terrain. This survey, therefore, constitutes a significant test of current scanning laser altimetry technology.

Peyto Glacier, at the northern end of the Icefield, has been a part of the national glacier mass balance program since 1966. Field \& photogrammetric work associated with glacier mass balance assessment [6] is time consuming, costly \& often of low spatial resolution [1]. As such, the National Glaciology Program at GSC is investigating "remote" techniques for monitoring mass balance [7]. In addition, extending the Peyto mass balance record back in time has been an objective in previous projects [5]. A recent study attempted this by constructing several glacier digital elevation models from archived photography \& computing volumetric changes [8]. Due to a scarcity of control points, however, it is thought that LiDAR data in "off-ice" areas may provide better ground control.

Simulating runoff from glacier areas requires melt models. Slope, aspect, \& elevation are topographic features that influence radiation received, \& therefore the surface melt budget. For modelling efforts in such areas, it is difficult to obtain high resolution DEMs \& the topographic parameters may be only roughly approximated. High resolution LiDAR data of this topographically complex glacierised basin is, therefore, ideal for investigating radiation loading scaling issues [2]. An overview of this study will be presented.

\section{DATA ACQUISITION \& PROCESSING}

Airborne laser altimetry combines knowledge of the speed of light, the location \& orientation of the laser head in 4 dimensional space \& the time between laser pulse transmission \& reception to determine a fixed co-ordinate on the ground. Continued "pulsing" in this configuration will result in a "profile" of ground elevations. This technology has been successfully utilised in various glaciological applications over Greenland [9] \& mountain glaciers in Alaska [10]. In scanning altimetry, laser pulses are scanned left \& right perpendicular to the flight line resulting in a "saw tooth" pattern of ground survey points. The only known use of this technology over alpine glacierised terrain was during testing of a prototype Optech Inc. airborne laser terrain mapper (ALTM) in 1995 [11]. The study demonstrated high correspondence between adjacent laser shots with absolute errors of around $10 \mathrm{~cm}$.

The Wapta Icefield survey was conducted in October 2000 using an Optech Inc. 1225 ALTM mounted in a Piper Navajo. This ALTM differed from that used in [11] by having a higher pulse frequency of $25 \mathrm{kHz}$, a dual first/last pulse capability with intensity (at $1065 \mathrm{~nm}$ ). Two survey polygons were flown: SE - NW along the continental divide \& SSW - NNE along the axis of Peyto Glacier 
(Fig.1). Survey settings are summarized in Table 1. The flight direction alternated as the survey progressed eastwards over the large polygon $\&$ the altitude was dropped by $\sim 50 \mathrm{~m}$ from line to line to account for the eastward decline in ground elevation. For the polygon over Peyto, a "racetrack" configuration was flown due to strong winds. The aircraft, \& therefore laser head, trajectory was computed using differential GPS from a ground receiver located in the NE corner of the survey area.

TABLE I

Survey Parameters

\begin{tabular}{llllll}
\hline Input & \multicolumn{3}{c}{ Output } & \multicolumn{3}{c}{ (height $\mathrm{m}$ above ground level) } \\
Laser \& Flight Settings & & Parameter & 900 & 1600 & 2300 \\
\hline Repetition rate & $25 \mathrm{kHz}$ & X spacing & 1.40 & 1.40 & 1.40 \\
Scanner frequency & $20 \mathrm{~Hz}$ & Y spacing & 1.05 & 1.86 & 2.68 \\
Scan angle & $+/-20 \mathrm{deg}$ & Foot print & 0.24 & 0.41 & 0.59 \\
Aircraft velocity & $55 \mathrm{~m} / \mathrm{s}$ & Swath width 655 & 1165 & 1674 \\
Flying altitude & & $\sim 4000 \mathrm{~m}$ & & \\
Max. bank angle & $20 \mathrm{deg}$ & & & & \\
Line spacing & $500 \mathrm{~m}$ & & & & \\
\end{tabular}

The GPS trajectory, laser ranges, scan position \& inertial navigation system data were combined within Optech's "Realm" ALTM software to compute the XYZ coordinates of every returned laser pulse. First/last pulses \& associated intensities from every laser transmission were outputted. Dual pulse data are useful in areas where the ground surface is not solid, e.g. forests. In such cases, first pulse is often associated with the canopy \& last pulse the underlying ground. Intensity readings have an 8-bit range and when plotted, a single channel image similar in nature to a black \& white photograph usually results. For subsequent analyses, last pulse XYZ data were gridded to generate raster DEMs.

\section{ALTM SURVEYS IN HIGH RELIEF TERRAIN}

The flight was turbulent due to low flying (900-2300 magl) with updrafts \& crosswinds making it difficult to stay on line. Frequently the aircraft banked at angles exceeding $30^{\circ}$ (beyond recommended limits). However, despite poor flying conditions, only two narrow strips were re-flown to achieve complete ground coverage.

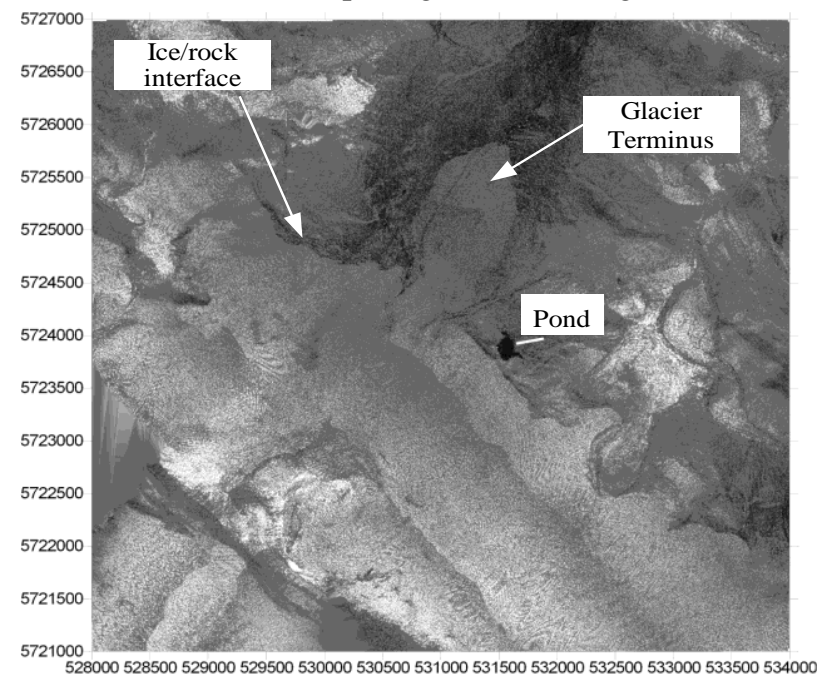

Fig. 2. Laser pulse intensity image over Peyto glacier (UTM co-ords)

Following post processing, the airborne GPS trajectory was found to be excellent, displaying an RMS error of $<5$ $\mathrm{cm}$ for most of the 90-minute survey. Final processing and quality control of the data was postponed until ground data for control \& calibration purposes could be collected. From preliminary analysis, it is apparent that good correspondence exists between overlapping swaths \& adjacent data points $(<20 \mathrm{~cm}$ for all elevations). In addition, laser return losses (dropouts) averaged 5\% across the entire range of elevations. Dropouts increased to $100 \%$ over areas of low altitude ponds \& lakes but were zero over icefield areas. Thus, the LiDAR DEM is considered most accurate over the accumulation zone of glaciers where standard photogrammetry tends to be least reliable [11]. Fig. 2. illustrates the pattern of laser intensities over Peyto Basin. Intensities are greatest at high elevations, over snow and for slopes normal to the laser pulse. There is some variability across scans over the icefield due to specular snow characteristics \& sloping surfaces. Laser shot density was better than 1 per $\mathrm{m}^{2}$ at high elevations and around 1 per $2 \mathrm{~m}^{2}$ in valley bottoms.

\section{GLACIOLOGICAL APPLICATIONS}

An overview of the LiDAR mass balance assessment is provided in [1] \& will not be discussed here. However, there are many glaciological uses for high-resolution DEMs over rapidly changing glacier surfaces. Fig. 3. is a shaded relief $2 \mathrm{~m}$ raster DEM of Peyto Glacier terminus with some glaciological features highlighted. This DEM facilitates feature recognition \& measurement that would not be possible using other techniques. For example, crevasses, moraines, melt streams \& moulins (sink-holes) are all visible $\&$ could be measured if desired. A constraint to modelling processes in remote glacierised basins is a lack of high-resolution physiographic data. LiDAR DEMs could improve our ability to model glacio-hydrological \& meteorological processes such as ice melt and flow routing at finer resolutions than is currently possible.

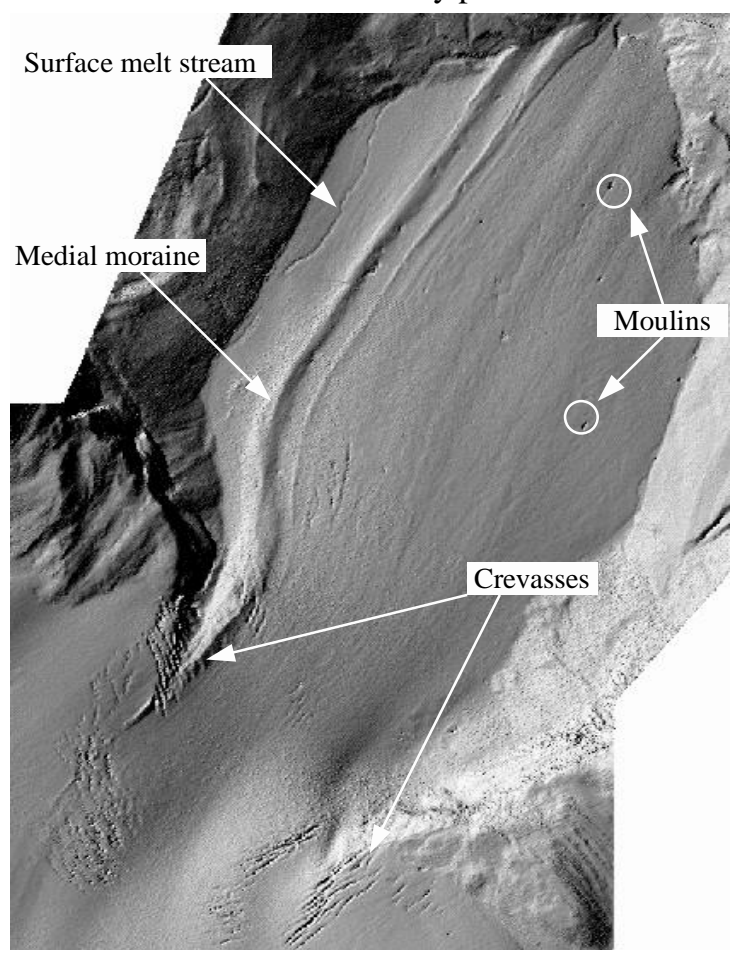

Fig. 3. Last pulse data over Peyto terminus, gridded at $2 \mathrm{~m}$ resolution.

\section{RADIATION LOADING SCALE ISSUES}

The Peyto Basin LiDAR data (Fig. 2) were gridded to $25 \mathrm{~m} \& 2.5 \mathrm{~m}$ resolutions, imported to ArcInfo \& a radiation-loading model applied. Solar geometry equations were taken from Oke [12], direct shadowing was computed in ArcInfo \& an empirical diffuse radiation component was 
added. Maximum diffuse sky radiation was assumed to be $10 \%$ of beam radiation incident on a horizontal plane then reduced for individual pixels according to a "skyview" factor estimated from slope \& elevation. Terrain irradiance was not considered in this analysis. A more thorough explanation of the study is found in [2].

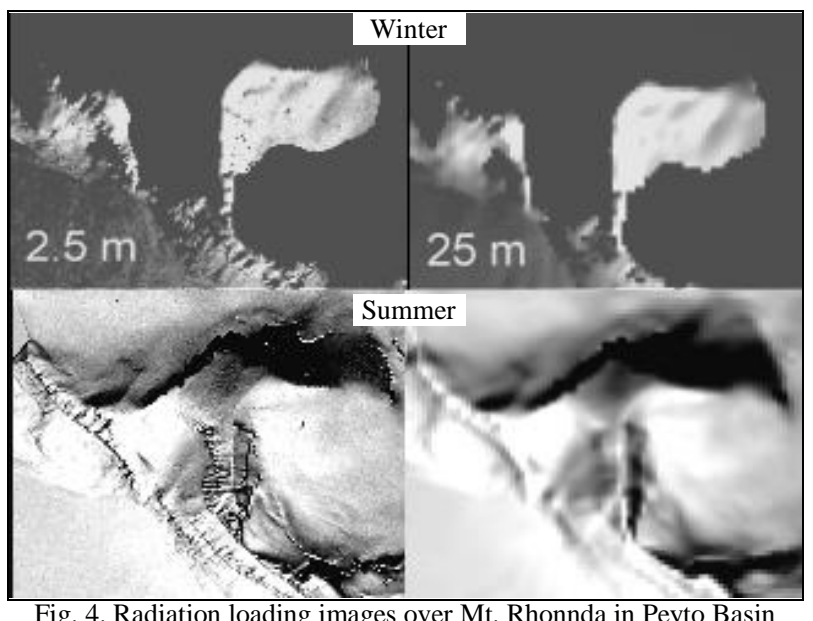

Extreme examples of modeled radiation loading at both resolutions over a peak in Peyto Basin are provided in Fig. 4. The images were computed for December $21^{\text {st }}$ at 09:00 (top) \& June $21^{\text {st }}$ at 12:00. Shading represents illumination conditions although the brightness scales differ between summer \& winter. Calculated radiation loading statistics are sumarised in Table II. A simple observation is that in the $2.5 \mathrm{~m}$ image micro-topographic features can lead to shadows in illuminated areas \& bright pixels in areas of shadow; ground surface texture has a pronounced effect on local radiation loading patterns.

TABLE II

Radiation loadings for both resolutions \& image difference statistics

\begin{tabular}{lllllll}
\hline Statistic & \multicolumn{3}{c}{ Summer } & \multicolumn{3}{c}{ Winter } \\
\hline \multirow{3}{*}{ Min } & $25 \mathrm{~m}$ & $2.5 \mathrm{~m}$ & difference & $25 \mathrm{~m}$ & \multicolumn{1}{c}{$2.5 \mathrm{~m}$} & difference \\
\cline { 2 - 7 } & 100.8 & 100.0 & -855.2 & 10.7 & 10.7 & -96.8 \\
Mean & 1165.5 & 1168.0 & +949.2 & 127.3 & 143.8 & +94.1 \\
Std dev. & 173.5 & 908.4 & +5.2 & 20.6 & 20.3 & +0.3 \\
\hline
\end{tabular}

Some of the effects of scale on radiation models were investigated by subtracting the $2.5 \mathrm{~m}$ Peyto Basin loading images from the $25 \mathrm{~m}$ images (Fig. 5). Summaries of the statistics for the difference images are provided in Table II. In Fig. 5, light pixels indicate that the $25 \mathrm{~m}$ image had a higher computed radiation load than for the corresponding area of the $2.5 \mathrm{~m}$ image \& vice versa. The data presented in Table II indicates that the range of radiation loads is greatest for the high resolution DEM due to higher maximum values. However, despite higher maximums, the means are lower \& the $25 \mathrm{~m}$ images tend to overestimate the total radiation load slightly. This is due to greater surface texture at higher resolutions, which leads to a higher occurrence of local shadowing. In Fig. 5 the greatest differences between the two resolutions occur in areas of steep slope or surface texture \& in areas of sharp transition, such as along ridges or direct beam shadow edges. Slope \& orientation of the edge relative to the sun determine whether the error will be positive or negative. For example, radiation loads on ridges perpendicular to \& facing the sun tend to be underestimated. Systematic overestimation of radiation occurs at lower spatial resolutions over the tops of gulleys with an underestimation at their bases.

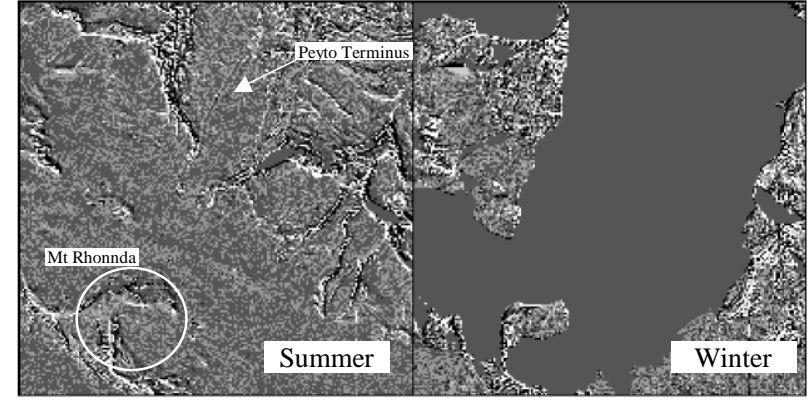

Fig. 5. Radiation loading difference over Peyto Basin (25m pixels)

\section{CONCLUDING REMARKS}

This combined government, industrial, \& academic research effort has demonstrated that airborne LiDAR elevation data are reliable over varying ground covers \& high relief terrain despite difficult flying conditions. The variability in IR intensity due to high elevation ranges reduces the value of LiDAR for spectral applications. However, the rapid collection \& dissemination of this kind of data make airborne LiDAR a cost effective supplemental tool for glaciological mapping applications such as mass balance monitoring or for high resolution modelling efforts. To this end, the high-resolution data over Peyto Basin have been used to investigate systematic biases in radiation loading between pixel sizes of $25 \& 2.5$ $\mathrm{m}$. It has been shown that at the $25 \mathrm{~m}$ resolution, basin wide radiation loading is slightly overestimated $\&$ there are systematic errors associated with edge effects.

\section{ACKNOWLEDGEMENTS}

Parks Canada \& Terry Beck for logistical assistance. Funding was partially provided by the Canadian Govt. Climate Change Action Fund \& the Prairie Adaptation Research Co-operative.

\section{REFERENCES}

[1] Demuth, M., Hopkinson, C., Sitar, M., Pietroniro, A. \& Chasmer, L., Airborne laser terrain mapping of Peyto Glacier \& Wapta Icefields, Canada: first results \& future prospects. Annals Glaciol. In press.

[2] Chasmer, L. \& Hopkinson, C. Using airborne LiDAR, Landsat \& ArcInfo GIS to assess scale induced radiation-loading errors in a glacierised basin. Proc. $58^{\text {th }}$ Eastern Snow Conference, in press.

[3] Stanley, A.D., A pilot study for an inventory of the glaciers in the Rocky Mountains: Inventory of Glaciers in the Waputik Mountains. In: Perennial Ice \& Snow Masses, UNESCO-IASH Technical Papers in Hydrology, 1, 36-46, 1970

[4] Hopkinson, C. The Net Volumetric Loss of Glacier Cover Within the Bow Valley Above Banff, 1951 - 1993. Proc. Joint Eastern \& Western Snow Conferences, Banff, 1997.

[5] Hopkinson, C. \& Young, G.J., "The effect of glacier wastage on the flow of the Bow River". Hydrological Processes, 12, 10-11, pp1745-1763, 1998

[6] Østrem, G., Repeated glacier mapping for hydrological purposes: water power planning. Annals of Glaciology 8, 135-140, 1986

[7] Demuth, M.N. \& Pietroniro, A. Inferring glacier mass balance using RADARsat: results from Peyto Glacier, Canada. Geografiska Annaler 81A(4): 521-540, 1999

[8] Sitar, M., Hopkinson, C., Demuth, M.N. \& Brooks, R. Using photogrammetrically derived DEMs for improving estimates of glacier mass balance back casting, Peyto Glacier, Canada, 19491993. Proc. 58 ${ }^{\text {th }}$ Eastern Snow Conference, in press.

[9] Krabill, W.B. et al., Greenland ice sheet thickness changes measured by laser altimetry. Geo-phys. Res. Lett., 22 (17), 2341-2344, 1995.

[10] Echelmeyer, K.A. et al., Airborne surface profiling of glaciers: a case study in Alaska. J. Glaciol., 42 (142), 538-547, 1996.

[11] Kennet, M. \& Eiken, T., Airborne measurement of glacier surface elevation by scanning laser altimeter. Annals Glaciol., 24, $235-$ 238, 1997

[12] Oke, T.. Boundary Layer Climates. (2 ${ }^{\text {nd }}$ edn), Routledge, London, 435pp, 1995 